\title{
Risperidone vs olanzapine in treatment of schizophrenia: a double blind clinical trial
}

\begin{abstract}
Objective: While schizophrenia usually has an persistent recurring sequence, any kind of pharmaceutical advancement planned for attenuation of positive and negative symptoms may aid to reduce its unrelenting chronic sequence. Risperidone and olanzapine, as Second Generation Antipsychotic agents (SGAs), have been developed to come across this necessity. In the current assessment, effectiveness and safety of these two atypical antipsychotics has been compared with each other.

Method: 60 female schizophrenic inpatients, entered randomly into 2 contemporaneous groups to take part in a twelve-week, double-blind trial for random assignment to risperidone or olanzapine ( $\mathrm{n}=30$ in each group). While the main outcome measures included Scale for Assessment of Negative Symptoms (SANS) and Scale for Assessment of Positive Symptoms (SAPS), the Schedule for Assessment of Insight (SAI), Clinical Global Impressions-Severity Scale (CGI-S) and Simpson Angus Scale (SAS) as well were used as ancillary measures. Treatment efficacy was analyzed by $t$ test, and repeated -measures analysis of variance (ANOVA). Response was defined as a reduction of $20 \%$ or more in total scores of SANS and SAPS.
\end{abstract}

Results: According to the findings, both of risperidone and olanzapine were significantly valuable for amelioration of positive symptoms $(p<0.001 \& p<0.0001$, respectively). But respecting negative symptoms, only olanzapine ameliorated them significantly $(\mathrm{p}<0.001)$. SAI, too, was enhanced significantly by means of olanzapine $(\mathrm{p}<0.02)$. CGI-S revealed significant progress in both of risperidone and olanzapine $(\mathrm{p}<0.05$ and $\mathrm{p}<0.04$, respectively). SAS, as well, indicated significant intensification in the risperidone group $(\mathrm{p}<0.0001)$.

Conclusion: While both atypical antipsychotics were valuable in management of schizophrenia, olanzapine showed more effectiveness in comparison with risperidone.

Keywords: risperidone, olanzapine, schizophrenia, antipsychotic drugs, psychotic syndromes
Volume 5 Issue 2 - 2018

\author{
Saeed Shoja Shafti, Mahsa Gilanipoor \\ University of Social Welfare and Rehabilitation Sciences \\ (USWR), Iran
}

\begin{abstract}
Correspondence: Saeed Shoja Shafti, Professor of Psychiatry, University of Social Welfare and Rehabilitation Sciences (USWR), Razi Psychiatric Hospital, Tehran, Iran, Postal code |8669-5889|, Po Box |8735-569, Fax 0098-2|-3340|604, Tel 0098-21-3340 I220, Email ssshafti@gmail.com
\end{abstract}

Received: January 24, 2018 | Published: April 10, 2018
Abbreviations: WHO, world health organization; SGAs, second generation antipsychotics; SANS, scale for assessment of negative symptoms; SAPS, scale for assessment of positive symptoms; CGI-S, clinical global impressions-severity scale; SAI, schedule for assessment of insight; SAS, Simpson Angus Scale; ITT, intention-totreat; LOCF, last observation carried forward; FGAs, first generation antipsychotics; PANSS, positive and negative symptoms scale

\section{Introduction}

Traditionally, schizophrenia has been at the core of psychiatry and is closest to the community idea of insanity. While the incidence of schizophrenia in general public is about $1 \%$ and so it is not the most common illness, according to the World Health Organization (WHO) it accounts for a noteworthy percentage of psychiatric sickness and also, it is in the topmost ten reasons of incapacity. ${ }^{1,2}$ The nature of schizophrenia, containing inability to work, mental deficiency and breakup of personality makes it principally a damaging sickness for patients, relatives, and the public. ${ }^{2}$ Though the schizophrenic disorders are generally characterized by important and distinctive troubles in the processes of perception and thinking, and by incongruous or dulled affect, awareness and intelligent capability are usually preserved. Nonetheless, cognitive deficits may develop in the course of illness. The problem comprises the most basic functions that give the typical person a sense of self-direction, distinctiveness and individuality. The most interior moods, opinions, and actions are often sensed to be shared or recognized by others, and some disbelieves may grow, which accept as true that unusual or paranormal powers are at work to impact the troubled individual's beliefs and activities in ways that are a lot strange. ${ }^{3}$ On the other hand, generally, thirty to frothy percentage of schizophrenics may show an inadequate or unfortunate answer to First Generation Antipsychotics (FGAs), ${ }^{4}$ and up to half of them may experience severe adverse effects due to those drugs. ${ }^{5}$ Present-day management protocols mention using one of the Second Generation antipsychotics (SGAs), other than clozapine, as a first line of treatment for schizophrenia. Atypical antipsychotics, in contrast to conventional antipsychotics, have a low incidence of extrapyramidal adverse effects. ${ }^{6}$ Consequently, the motivation for development of novel medicines for management of schizophrenia has moved to manufacture medications capable of relieving negative symptoms, which are usually resistant to conventional antipsychotic drugs, ${ }^{7,8}$ and, likewise, to produce medications less probable to induce extra-pyramidal adverse effects. Initially, SGAs seemed to be more effectual than FGAs. However, in a study for comparing the special effects of FGAS with SGAs, the later group was no more effective than the first ones in management of schizophrenia, even regarding the negative symptoms. ${ }^{9}$ Risperidone is a benzisoxazole 
derivative with the highest attraction to serotonin 5-HT2, histamine H1, $\alpha 1$-adrenergic, and dopamine D2 receptors. In a number of clinical trials, Risperidone has been proved to be superior to FGAs. ${ }^{10}$ Olanzapine, as well, is a thienobenzodiazepine with great attraction to serotonin 5-HT2, histamine H1, $\alpha 1$-adrenergic, D1, and D2 dopamine receptors. ${ }^{11}$ Controlled clinical trials have shown that it has better efficacy and healthier side effect profile than haloperidol and according to some studies seems to be more efficient in management of negative symptoms. ${ }^{12-14}$ Both of these SGAs have been revealed to be effective in the management of psychotic syndromes. ${ }^{12,13,15,16} \mathrm{~A}$ range of appraisals for matching these two SGAs have brought about contradictory conclusions. For instance, Tran, et al. ${ }^{15}$ and Gureje, et al. ${ }^{16}$ had found that olanzapine, in comparison with risperidone, have some risk-versus-benefit advantage. According to Tran, the mentioned advantage of olanzapine was owing to its better effectiveness, evident alleviation of negative symptoms, superior maintenance, and lastly lesser incidence of adverse effects like hyperprolactinemia, sexual dysfunction and extra-pyramidal adverse effects. ${ }^{16}$ Likewise, Edgell, et al. ${ }^{17}$ and Rascati, et al. ${ }^{18}$ had declared that patients who received olanzapine were more probable to tolerate it in comparison with risperidone, and Feldman ${ }^{19}$, too, had declared that according to his findings in older patients and as regards improvement of negative symptoms, olanzapine was more effective than risperidone. ${ }^{19}$ On the other hand, in similar comparisons, Taylor ${ }^{20}$, Kasper $^{21}$ and Conley, ${ }^{22}$ in general, found comparable therapeutic outcomes for both of them. Since according to a number of references risperidone and olanzapine show better efficiency than other atypical antipsychotics, ${ }^{23}$ and if they have not been tried in treatment-resistant case, it would be a reasonable decision to test them before starting clozapine, ${ }^{23}$ then additional comparisons, in different samples, between these SGAs seems to be valuable. So, in the present assessment the effectiveness and safety of these two SGAs were compared, once more, with each other, regarding management of schizophrenia in a non-western patient population.

\section{Method}

60 female patients, as available sample in the chronic ward of the hospital, entered randomly into one of the selected groups, for random allocation to risperidone or olanzapine or ( $\mathrm{n}=30$ in each group), after firstly, complete description of the process for them and earning signed up agreement, and secondly, a minimum of seven days' washout period. Patients were identified as schizophrenic, according to Diagnostic and Statistical Manual of Mental Disorders, $4^{\text {th }}$ edition, text revision criteria. ${ }^{24}$ Prior treatments of the cases entailed a series of FGAs, like chlorpromazine, haloperidol, trifluperazine and perphenazine. While the assessor, staff and patients were uninformed of the recommended medications that were packed into alike capsules, the assessment had been performed through a double-blind, twelve-week trial. The tryout, as well, was approved by Academy's Therapeutic Morals Committee. Scale for Assessment of Negative Symptoms (SANS) ${ }^{25}$ and Scale for Assessment of Positive Symptoms (SAPS) were used as the main upshot procedures. ${ }^{26}$ Clinical Global Impressions-Severity Scale (CGI-S), ${ }^{27}$ Schedule for Assessment of Insight (SAI), ${ }^{28}$ and lastly Simpson Angus Scale (SAS), ${ }^{29}$ were, as well, used as ancillary measures. The length of the study was twelve weeks. Both of these drugs were prescribed according to practice guidelines and standard titration protocols, ${ }^{30}$ and in accordance to the following regimen: $1 \mathrm{mg}$ /day of risperidone or $5 \mathrm{mg} /$ day of olanzapine at baseline up to $2 \mathrm{mg}$ /day of risperidone and $10 \mathrm{mg} /$ day olanzapine at the end of the first week. Weekly interval increments of $2 \mathrm{mg}$ for risperidone and
$5 \mathrm{mg}$ for olanzapine, individually and according to clinical situation, up to maximum of $8 \mathrm{mg}$ and $25 \mathrm{mg}$ for resperidone and olanzapine, respectively, at week five. The $5^{\text {th }}$ week dose stayed unbroken up to the conclusion of the research. Elimination norms in the present assessment involved: Any other diagnosis in axis I except than schizophrenia, recognized medicinal or neural illness, consumption of other SGAs or simultaneous medications such as antidepressants or mood stabilizers, and lastly any instance using depot antipsychotics. Also, no other psycho-social intervention or psychotropic medication, in the course of the assessment, was prescribed or permitted for cases that had participated in the trial. The patients were assessed by means of SANS and SAPS at starting point (week 0), and weeks four, eight and twelve. The supplementary measures were scored at starting point and at the completion of the evaluation.

\section{Statistical analysis}

The primary analysis was carried out according to the intention-totreat (ITT), last- observation -carried-forward (LOCF) approach, and participants were matched on baseline features by means of $t$ tests. While statistical significance was defined as a 2 -sided $\mathrm{p}$ value $<$ or $=$ to 0.05 , treatment effectiveness was explored by $t$ test and repeated -measures analysis of variance (ANOVA) comparing both groups over twelve weeks. Cohen's Standard (d) and Correlation measures of effect size(r) were used for comparing starting- point to end-point variations in main outcome measures. MedCalc, version 9.4.1.0, was used as statistical software tool for analysis.

\section{Results}

Assessment for effectiveness was based on data from comparable number of patients in olanzapine and risperidone groups. While groups were initially analogous and demographic and diagnostic variables were analogous (Table 1), six patients $(20 \%)$ in the risperidone group and five of them $(16 \%)$ in the olanzapine group left the tryout in the second half of the assessment due to reluctance or adverse effects of the recommended drugs. At the end of the present evaluation, quantifiable amelioration, which had been defined as at least twenty percent reduction in total scores of SAPS and SANS, was evident in $63.33 \%$ \& $36.66 \%$ of cases in the risperidone group and $71.66 \% \& 48.33 \%$ of the participants in the olanzapine group, respectively. In keeping with the results, while negative symptoms exhibited significant improvement only by olanzapine $(p<0.001)$, both of risperidone and olanzapine were significantly effectual regarding amelioration of positive symptoms $(\mathrm{p}<0.001 \& \mathrm{p}<0.0001$, respectively) (Table 2). Decrease of mean total score of SAPS was around $\% 5.65$ and $\% 13.59$ on behalf of risperidone and olazapine, respectively (Figure 1). Improvement of negative symptoms, too, was around $\% 2.23$ and $\% 7.41$ for risperidone and olanzapine, respectively (Table 2) (Figure 2). Likewise, repeated-measures analysis of variance (ANOVA) as regards SAPS displayed significant amelioration by risperidone and olanzapine $[F(3,116)=0.719 p<0.05$ $\mathrm{SS}=2834.76 \mathrm{MSe}=1146.12$ and $\mathrm{F}(3,116)=0.734 \mathrm{p}<0.02 \mathrm{SS}=2994.65$ $\mathrm{MSe}=1359.17$, respectively]. In addition, Split-plot (Mixed) design ANOVA revealed significantly more efficacy in support of olanzapine $[\mathrm{F}(3,116)=0.761 \mathrm{p}<0.05 \mathrm{SS}=2013.65 \mathrm{MSe}=1267.10]$. But, whereas repeated-measures analysis of variance (ANOVA), regarding SANS, indicated non-significant modifications in the risperidone group $[\mathrm{F}$ $(3,116)=0.734 \mathrm{p}<0.08 \mathrm{SS}=1774.59 \mathrm{MSe}=1152.18]$, it was significant with respect to olanzapine $[\mathrm{F}(3,116)=0.734 \mathrm{p}<0.04 \mathrm{SS}=2021.65$ $\mathrm{MSe}=1161.08]$. Besides, though analysis by means of t-test at 
week twelve had disclosed significant superiority of olanzapine in comparison with risperidone, regarding SANS $(\mathrm{p}<0.04)$ and SAPS $(\mathrm{p}<0.001)$ (Table 3), but Split-plot (Mixed) design ANOVA could not support that conclusion with regard to SANS $[\mathrm{F}(3,116)=0.633$ $\mathrm{p}<0.09 \mathrm{SS}=2891.36 \mathrm{MSe}=1278.09]$. Concerning ancillary measures, while SAI showed significant enhancement by means of olanzapine $(p<0.02)$ and non-significant progress by risperidone $(p<0.31)$, CGI-S was significantly upgraded in both of the groups $(p<0.05 \&$ $\mathrm{p}<0.04$ for risperidone and olanzapine, respectively) (Table 2). In addition, SAS presented intensification of extra-pyramidal adverse effects with around $31.91 \%$ and $12.19 \%$ increase by risperidone $(\mathrm{p}<0.0001)$ and olanzapine $(\mathrm{p}<0.06)$, respectively (Table 2$)$. Betweengroup analysis, also, revealed significantly worse state on behalf of risperidone $(\mathrm{p}<0.04)$ (Table 3$)$. So, such an additional amplification of extra-pyramidal side effects and consequently secondary negative symptoms by risperidone, might describe, in some measure, the lesser alleviation of that cluster of symptoms by risperidone in the current evaluation. Since our sample size was small, the Effect Size
(ES) was examined for alterations on the main upshot measures at the end of tryout. Outcomes indicated a great ("d" or " $\mathrm{r}$ " $=$ or $>0.8$ or 0.3 , respectively) evident alleviation of SAPS by olanzapine and intermediate amelioration (" $\mathrm{d}$ " or " $\mathrm{r}$ " $=0.5$ or 0.2 , respectively) by risperidone. Likewise, outcomes displayed intermediate and slight ("d" or "r" $=$ or $<0.2$ or 0.1 , respectively) improvement of SANS by Olanzapine and Risperidone, respectively. The mean modal dose of risperidone and olanzapine throughout the current appraisal was $6.32 \pm 1.68 \mathrm{mg} /$ day and $20.49 \pm 4.51 \mathrm{mg} /$ day, respectively. During this trial, extra-pyramidal adverse effects were evident in around $16.66 \%$ of patients in the Olanzapine group and $48.33 \%$ of the cases in the risperidone group $(\mathrm{p}<0.03)$. In contrast, weight gain was significantly more marked in olanzapine group $(46.66 \%)$ in comparison with risperidone group $(16.66 \%)(\mathrm{p}<0.03)$. The average weight gain was about $0.7+/-0.2 \mathrm{~kg}$ in the risperidone group and $3.4+/-0.8 \mathrm{~kg}$ in the olanzapine group $(p<0.0001)$. Post-hoc power analysis showed an intermediary power equal to 0.60 with regard to this assessment.

Table I Demographic Characteristics of Participants

\begin{tabular}{llllll}
\hline Drugs & Olanzapine $(\mathbf{N}=\mathbf{3 0})$ & Risperidone $(\mathbf{N}=\mathbf{3 0})$ & $\mathbf{T}$ & $\mathbf{P}$ & $\mathbf{9 5 \%} \mathbf{C I}$ \\
\hline Demographic Variables & & & & \\
\hline Age, y & $36.89 \pm 3.52$ & $38.44 \pm 4.91$ & 1.283 & 0.2 & -0.76 to 3.48 \\
Age at onset, y & $22.48 \pm 3.74$ & $23.62 \pm 4.91$ & 0.923 & 0.36 & -1.25 to 3.17 \\
Duration of illness, y & $6.83 \pm 1.63$ & $6.39 \pm 1.58$ & 0.969 & 0.33 & -2.28 to 3.24 \\
No of Prior episodes: Mean \pm SD & $7.18 \pm 2.13$ & $6.82 \pm 1.51$ & 0.65 & 0.51 & -1.46 to 0.74 \\
Baseline SAPS & $63.72 \pm 3.73$ & $62.17 \pm 4.08$ & 1.221 & 0.22 & -0.87 to 3.57 \\
Baseline SANS & $46.37 \pm 3.26$ & $47.02 \pm 3.95$ & 0.635 & 0.52 & -0.11 to 4.01 \\
Baseline SAI & $3.59 \pm 0.73$ & $3.63 \pm 1.02$ & 0.159 & 0.87 & -0.46 to 0.54 \\
Baseline SAS & $0.36 \pm 0.06$ & $0.32 \pm 0.09$ & 1.849 & 0.07 & -0.08 to 0.003 \\
Baseline CGI-S & $3.71 \pm 1.13$ & $3.28 \pm 078$ & 1.566 & 0.12 & -0.98 to 0.12
\end{tabular}

Abbreviations: SAPS, scale for assessment of positive symptoms; SANS, scale for assessment of negative symptoms; CGI-S, clinical global impressions-severity scale; SAI, schedule for assessment of insight; SAS, simpson angus scale

Table 2 Intra-Group Analysis of Different Outcome Measures between Baseline and week 12

\begin{tabular}{|c|c|c|c|c|c|c|c|c|c|c|}
\hline Measure & Olanzaoine & Olanzapine & $\mathbf{T}$ & $\mathbf{P}$ & $95 \% \mathrm{CI}$ & Risperidone & Risperidone & $\mathbf{T}$ & $\mathbf{P}$ & $95 \% \mathrm{CI}$ \\
\hline & Baseline & Week 12 & & & & Baseline & Week 12 & & & \\
\hline SAPS & $63.72 \pm 3.73$ & $55.06 \pm 3.31$ & 8.68 & 0.0001 & -10.66 to -6.65 & $62.37 \pm 4.08$ & $58.84 \pm 2.98$ & 3.49 & 0.001 & $\begin{array}{l}-5.56 \text { to } \\
-1.50\end{array}$ \\
\hline SANS & $46.37 \pm 3.26$ & $42.93 \pm 3.86$ & 3.4 & 0.001 & -5.47 to -1.40 & $47.02 \pm 3.95$ & $45.97 \pm 3.17$ & 1.03 & 0.3 & $\begin{array}{l}-0.98 \text { to } \\
3.08\end{array}$ \\
\hline CGI-S & $3.71 \pm 1.13$ & $3.11 \pm 1.07$ & 1.93 & 0.04 & -1.22 to 0.02 & $3.28 \pm 078$ & $2.97 \pm 0.02$ & 1.88 & 0.05 & $\begin{array}{l}-0.004 \text { to } \\
0.62\end{array}$ \\
\hline SAI & $3.59 \pm 0.73$ & $3.94 \pm 0.17$ & 2.33 & 0.02 & 0.04 to 0.65 & $3.63 \pm 1.02$ & $3.91 \pm 0.92$ & 1.01 & 0.31 & $\begin{array}{l}-0.83 \text { to } \\
0.27\end{array}$ \\
\hline SAS & $0.36 \pm 0.06$ & $0.41 \pm 0.12$ & 1.86 & 0.06 & -0.004 to 0.10 & $0.32 \pm 0.09$ & $0.47 \pm 0.08$ & 6.22 & 0.0001 & $\begin{array}{l}0.10 \text { to } \\
0.19\end{array}$ \\
\hline
\end{tabular}

Abbreviations: SAPS, scale for assessment of positive symptoms, SANS, scale for assessment of negative symptoms; CGI-S, clinical global impressions-severity scale; SAI, schedule for assessment of insight, SAS, simpson angus scale 
Table 3 Between-Group Analysis of Different Outcome Measures at weeks 4, 8 and I2

\begin{tabular}{|c|c|c|c|c|c|}
\hline Measures & Olanzapine $\mathbf{N}=30$ & Risperidone $\mathbf{N}=\mathbf{3 0}$ & $\mathbf{T}$ & $\mathbf{P}$ & $95 \% \mathrm{Cl}$ \\
\hline SAPS- $4^{\text {th }}$ week & $62.36 \pm 4.81$ & $62.02 \pm 3.51$ & 0.28 & 0.776 & -2.73 to 2.05 \\
\hline SAPS- $8^{\text {th }}$ week & $60.19 \pm 3.75$ & $61.43 \pm 3.26$ & 1.24 & 0.218 & -0.75 to 3.23 \\
\hline SAPS- $12^{\text {th }}$ week & $55.06 \pm 3.31$ & $58.84 \pm 2.98$ & 4.24 & 0.001 & 1.98 to 5.57 \\
\hline SANS-4 $4^{\text {th }}$ week & $45.58 \pm 2.96$ & $46.92 \pm 2.83$ & 1.63 & 0.108 & -0.30 to 2.98 \\
\hline SANS-8 ${ }^{\text {th }}$ week & $45.02 \pm 3.18$ & $46.6 I \pm 4.23$ & 1.5 & 0.139 & -0.53 to 3.71 \\
\hline SANS-1 $2^{\text {th }}$ week & $41.93 \pm 2.86$ & $45.97 \pm 3.17$ & 2.06 & 0.04 & 0.04 to 3.47 \\
\hline SAl $-12^{\text {th }}$ week & $3.94 \pm 0.17$ & $3.91 \pm 0.92$ & 0.16 & 0.87 & -0.34 to 0.40 \\
\hline SAS- $12^{\text {th }}$ week & $0.4 I \pm 0.12$ & $0.47 \pm 0.08$ & 2.08 & 0.04 & 0.002 to 0.11 \\
\hline CGI-S-12 $2^{\text {th }}$ week & $3.11 \pm 1.07$ & $2.97 \pm 0.02$ & 0.65 & 0.51 & -0.29 to 0.57 \\
\hline
\end{tabular}

Abbreviations: SAPS, scale for assessment of positive symptoms, SANS, scale for assessment of negative symptoms; CGI-S, clinical global impressions-severity scale; SAI, schedule for assessment of insight, SAS, simpson angus scale

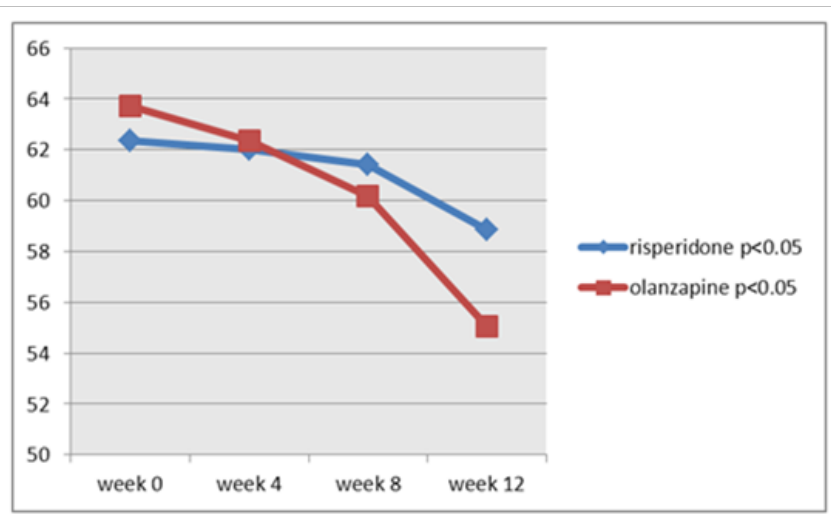

Figure I Changes of SAPS between baseline and week 12 .

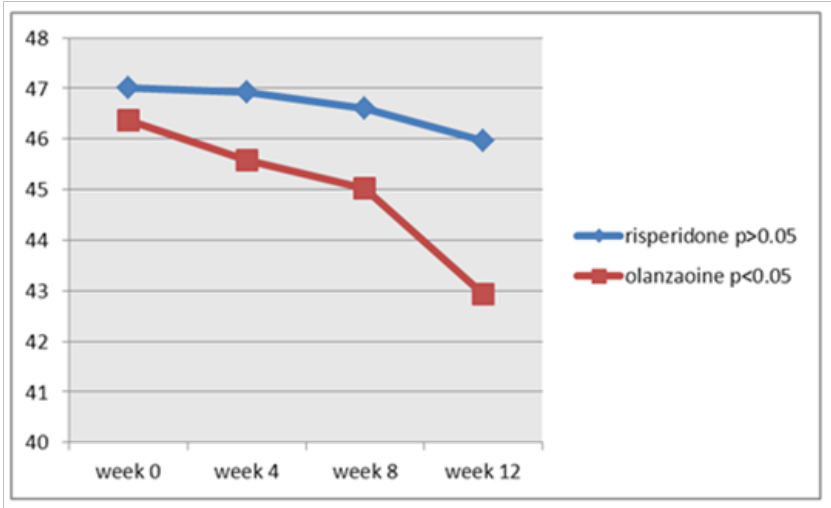

Figure 2 Changes of SANS between baseline and week 12.

\section{Discussion}

While management of schizophrenia needs to address basic areas such as deficit syndrome, cognitive insufficiencies, and unfortunate response to existing antipsychotic drugs, general concept regarding the underlying neurobiology of schizophrenia is continually and noticeably being enriched, based on neuroimaging and genetic studies. ${ }^{31}$ Despite the fact that antipsychotic drugs are effective in both the acute and maintenance treatment of schizophrenia and other psychotic disorders, they are unlike as regards their pharmacokinetics, overall efficacy/ effectiveness and acceptability, and so patients are unalike respecting response and tolerability. This different response means that there is no distinctive first-line antipsychotic appropriate for all. ${ }^{32}$ Moreover, While the FGAs and SGAs all share an interface with the dopamine D2 receptor in their pharmacological properties, with dissimilarities in the grade of selectivity and the more recent introduction of partial agonism as variations on the subject, it is so well understood that these medications do not manage the full spectrum of the ailment, nor do all patients respond to these drugs. There hence remains a huge unmet patient needs, and necessity of novel approaches for controlling them. ${ }^{33}$ Anyway, according to a major US-based publicly funded comparative assessment, tested patients, who had failed their first SGAs and were then randomly assigned to a different SGA, showed that cases that were changed to risperidone or olanzapine did better than those that had been switched to quetiapine or ziprasidone. ${ }^{23}$ This greater efficacy has been supported by a new survey that had compared a number of SGAs to FGAs and concluded that except clozapine, only, olanzapine, risperidone and amisulpride were superior to FGAs in efficacy; and over again by one more study comparing SGAs amongst themselves which proposes that risperidone and olanzapine may be more effective than others ${ }^{33}$ and there is no major difference among the other ones respecting effectiveness. ${ }^{33,34}$ This suggests that if a patient has not tried risperidone or olanzapine so far, it would be a rational choice to switch to these medications provided the side-effect balance is favourable. ${ }^{23}$ Back to our study, the main goal of the present investigation was to compare safety and efficacy of risperidone versus olanzapine in schizophrenic patients. According to the results of the current assessment both antipsychotics were efficient in decreasing the strictness of general psychotic symptoms, though patients who were treated by olanzapine had displayed a little more satisfying results in comparison with the other atypical drug, based on better upgrading in SANS, SAPS and to some extent SAI, and markedly a lesser amount of amplification of SAS. Furthermore, a meaningfully more proportion of patients, who were treated by olanzapine, responded with at least twenty percent enhancement in SANS and SAPS. In this regard, the general response in the present assessment was similar to a different comparable methodical research on a group of patients diagnosed as schizophreniform disorder, schizoaffective disorder or schizophrenia. ${ }^{16}$ The aforementioned tryout, as well, recounted that a considerably larger quantity of cases who were treated by olanzapine showed outstanding enhancement in Positive and Negative Symptoms 
Scale (PANSS), superior improvement in SANS and noticeably a lesser extent of extrapyramidal adverse effects. Instead, there are other trials with variable outcomes. For instance, in a study for comparing risperidone with olanzapine in management of patients suffering from schizoaffective disorder or schizophrenia, no substantial difference on the subject of effectiveness or extra-pyramidal adverse effects was evident. ${ }^{22}$ Furthermore, an additional similar comparative study showed that while risperidone caused greater improvements in psychotic symptoms in comparison with olanzapine, significantly more akathisia, as well, was observable by that.$^{35}$ Additional studies, too, may be found that have similar conclusions in support of risperidone. ${ }^{19,20}$ Possibly, employment of diverse efficiency procedures with different psychometric characteristics and unalike sample populations may describe, by some means, these contrary outcomes. Besides, because the increase in weight was outstandingly more prevalent by olanzapine, so this problem and associated metabolic adverse effects should be considered, at all times, by physicians. As regards risperidone, the similar caution is necessary with regard to extra-pyramidal side effects. While the outcomes of the current evaluation do not seem to be more conclusive, in comparison with the preceding trials, they may put forward the necessity for supplementary comparisons among SGAs. No doubt, gender-based sampling, small sample size, short duration of trial and lack of placebo arm were among the weaknesses of this trial.

\section{Conclusion}

While both atypical antipsychotics were valuable in management of schizophrenia, olanzapine showed more effectiveness in comparison with risperidone.

\section{Acknowledgements}

The authors gratefully acknowledge their dear colleague $\mathrm{S}$. Akbari (M.D.) and the Department of Research for their practical and financial support of this study.

\section{Conflict of interest}

The author declares no conflict of interest.

\section{References}

1. Harrison P, Geddes J, Sharpe M. Lecture Notes: Psychiatry. $10^{\text {th }}$ ed Oxford, UK, Wiley-Blackwell; 2011. 240 p.

2. Albert JS, Wood MW. Targets and Emerging Therapies for Schizophrenia 1st ed. Oxford, UK: Wiley-Blackwell; 2012. 494 p.

3. WHO. International Statistical Classification of Diseases and Related Health Problems (ICD-10). Geneva, Switzerland, World Health Organization; 1992. p. 85-109.

4. Lieberman JA. Prediction of outcome in first-episode schizophrenia. $J$ Clin Psychiatry. 1993;54 Suppl:13-17.

5. Kane JM, Lieberman JA. Adverse Effects of Psychotropic Drugs. New York, Guilford Press; 1992.

6. Burton N. Psychiatry. 2nd ed. Oxford, UK: Wiley-Blackwell; 2010. 240 p.

7. Saeed Shoja Shafti. Odyssey of 'Negative Symptoms' of Schizophrenia: Rehabilitation vs Stigmatization. Current Psychopharmacology. 2015;4(1):1-12

8. Shoja Shafti S, Jafarabad MS, Azizi R. Amelioration of deficit syndrome of schizophrenia by norepinephrine reuptake inhibitor. Ther $A d v$

\section{Psychopharmacol. 2015;5(5):263-270.}

9. Leucht S, Corves C, Arbter D, et al. Second-generation versus firstgeneration antipsychotic drugs for schizophrenia: a meta-analysis. Lancet. 2009;373(9657):31-41.

10. Moore NA, Tye NC, Axton MS, et al. The behavioral pharmacology of olanzapine, a novel "atypical" antipsychotic agent. J Pharmacol Exp Ther. 1992;262(2):545-551.

11. Beasley CM Jr, Tollefson GD, Tran P, et al. Olanzapine versus placebo and haloperidol: acute phase results of the North American double-blind olanzapine trial. Neuropsychopharmacology. 1996;14(2):111-123.

12. Tollefson GD, Beasley CM Jr, Tran PV, et al. Olanzapine versus haloperidol in the treatment of schizophrenia and schizoaffective disorders: results of an international collaborative trial. Am J Psychiatry. 1997;154(4):457465 .

13. Devlla MA, Tran P, Tollefson GD, et al. Standard olanzapine versus placebo and ineffective-dose olanzapine in the maintenance treatment of schizophrenia. Psychiatr Serv. 1997;48(12):1571-1577.

14. Marder SR, Meibach RC. Risperidone in the treatment of schizophrenia. Am J Psychiatry. 1994;151(6):825-835.

15. Tran PV, Hamilton SH, Kuntz AJ, et al. Double-blind comparison of olanzapine versus risperidone in the treatment of schizophrenia and other psychotic disorders. J Clin Psychopharmacol. 1997;17(5):407-418.

16. Gureje O, Miles W, Keks N, et al. Olanzapine vs risperidone in the management of schizophrenia: a randomized double-blind trial in Australia and New Zealand. Schizophr Res. 2003;61(2-3):303-314.

17. Edgell ET, Andersen SW, Johnstone BM, et al. Olanzapine versus risperidone. A prospective comparison of clinical and economic outcomes in schizophrenia. Pharmacoeconomics. 2000;18(6):567-579.

18. Rascati KL, Johnsrud MT, Crismon ML, et al. Olanzapine versus risperidone in the treatment of schizophrenia: a comparison of costs among Texas Medicaid recipients. Pharmacoeconomics. 2003;21(10):683-697.

19. Feldman PD, Kaiser CJ, Kennedy JS, et al. Comparison of risperidone and olanzapine in the control of negative symptoms of chronic schizophrenia and related psychotic disorders in patients aged 50 to 65 years. $J$ Clin Psychiatry. 2003;64(9):998-1004.

20. Taylor DM, Wright T, Libretto SE, et al. Risperidone Olanzapine Drug Outcomes Studies in Schizophrenia (RODOS) U.K. Investigator Group:Risperidone compared with olanzapine in a naturalistic clinical study: a cost analysis. J Clin Psychiatry. 2003;64(5):589-597.

21. Kasper S, Jones M, Duchesne I, et al. Risperidone \& olanzapine drug outcomes studies in schizophrenia (RODOS): health economic results of an international naturalistic study. Int Clin Psychopharmacol. 2001;16(4):189-196.

22. Conley RR, Mahmoud R. A randomized double-blind study of risperidone and olanzapine in the treatment of schizophrenia or schizoaffective disorder. Am J Psychiatry. 2001;158(5):765-774.

23. Rosenheck RA, Davis S, Covell N, et al. Does switching to a new antipsychotic improve outcomes? Data from the CATIE Trial. Schizophr Res. 2009;107(1):22-29.

24. APA. Diagnostic and Statistical Manual of Mental Disorders. $4^{\text {th }}$ ed. Washington, American Psychiatric Association; 2000.

25. Andreasen N. The Scale for Assessment of Negative Symptoms (SANS). University of Iowa, Department of Psychiatry, Iowa City, Iowa, 1981.

26. Andreasen N. The Scale for Assessment of Positive Symptoms (SAPS). University of Iowa, Department of Psychiatry, Iowa City, Iowa, 1984. 
27. David AS. Insight and Psychosis, Br J Psychiaty,1990;156:798-808.

28. Guy W. Clinical Global Impressions: ECDEU Assessment Manual for Psychopharmacology. Rockville, US Department of Health, Education and Welfare; 1976. $616 \mathrm{p}$.

29. Simpson GM, Angus JW. A rating scale for extrapyramidal side effects. Acta Psychiatr Scand Suppl. 1970;212:11-9.

30. Van Kammen DP, Marder SR. Serotonin-dopamin antagonists. In: Sadock BJ, Sadock VA, Editiors. Comprehensive Textbook of Psychiatry. $8^{\text {th }}$ ed. Kaplan \& Sadock's. Vol 2. Baltimore, USA: Lippincott Williams \& Wilkins; 2005:2455.

31. Tam GWC, Redon R, Carter NP, et al. The role of DNA copy number variation in schizophrenia. Biol Psychiatry. 2009;66(11):1005-1012.
32. Taylor D, Paton C, Kapur S. The Maudsley Prescribing Guidelines in Psychiatry. 11th ed. Oxford, UK: Wiley-Blackwell; 2012. 666 p.

33. Albert JS, Wood MW. Targets and Emerging Therapies for Schizophrenia, 1st ed. Oxford, UK: Wiley-Blackwell; 2012. p:1-3.

34. Shoja Shafti S, Kaviani H. Quetiapine versus aripiprazole in the management of schizophrenia. Ther Adv Psychopharmacol. 2015;5(3):166-171.

35. Ho BC, Miller D, Nopoulos P, et al. A comparative effectiveness study of resperidone and olazapine in the treatment of schizophrenia. $J$ Clin Psychiatry. 1999;60(10):658-663. 